05

\title{
Влияние закрепления дислокаций примесями на скорость ползучести алюминия
}

\author{
() А.И. Петров, М.В. Разуваева
}

Физико-технический институт им. А.Ф. Иофффе РАН, 194021 Санкт-Петербург, Россия

e-mail: An.Petrov@mail.ioffe.ru, M.Razuvaeva@mail.ioffe.ru

(Поступило в Редакцию 21 июня 2017 г.)

Приведены результаты оценки влияния подвижности дислокаций на скорость ползучести алюминия. Подвижность дислокаций на стационарной стадии ползучести изменяли закреплением дислокаций примесными атомами при нагреве образцов. Показано, что изменение скорости ползучести пропорционально доле атомов примеси, перешедшей из твердого раствора деформированного алюминия на дислокации.

DOI: 10.21883/JTF.2017.12.45209.2395

В работе [1] для ряда поликристаллических металлов (Al, Zn, Ti) был обнаружен эффект упрочнения (уменьшение скорости ползучести $\dot{\varepsilon}$ и рост времени до разрушения $t_{f}$ ) в результате промежуточного отжига образцов, выработавших 0.5-0.7 своей долговечности. Был сделан вывод, что уменьшение $\dot{\varepsilon}$ и рост $t_{f}$ связаны с залечиванием микроскопических пор размером $150-200 \mathrm{~nm}$, образовавшихся под нагрузкой на стационарной стадии крипа [2-4]. Анализ литературных данных показал, однако, что в сравнительно чистых поликристаллах поры образуются только на третьей стадии ползучести [5-7]. Образование пор в шейке обусловлено появлением дополнительных радиальных и тангенциальных напряжений [5], а кинетика накопления пор определяется величиной гидростатического напряжения $\sigma_{m}$, равного одной трети суммы трех главных компонент напряжения, имеющего смысл всестороннего растяжения в шейке [5,8]. Показано также, что при испытании таких металлов в условиях всестороннего сжатия поры развиваться не будут, если величина давления достаточна для компенсации растягивающего давления [8]. Эти данные дают основание считать сделанный ранее вывод о массовом образовании пор в процессе однородной деформации чистых металлов как и предлагаемую ранее поровую трактовку обнаруженного эффекта упрочнения недостаточно обоснованными.

Другая возможная причина наблюдаемого эффекта упрочнения может быть связана с уменьшением подвижности дислокаций вследствие закрепления их примесью. Действительно, известно что эффективным способом иммобилизации дислокаций является локальное увеличение концентрации примесных атомов вблизи дислокации и непосредственно на ней $[9,10]$. Сегрегация примесных атомов на дислокации обусловливает изменение скорости ползучести, а также появление больших значений энергии активации процесса ползучести в температурном интервале, где развивается деформационное старение $[11,12]$.
Целью настоящей работы является оценка температурного интервала закрепления дислокаций, степени насыщения дислокаций примесью и напряжения отрыва дислокаций от примеси, которое сопоставляли с наблюдаемым на опыте дополнительным упрочнением при ползучести алюминия.

Исследование проводили на образцах алюминия (99.96 wt.\%). Образцы в виде двойной лопатки с размером рабочей части $22 \times 2 \times 2 \mathrm{~mm}^{3}$ предварительно отжигали при $450^{\circ} \mathrm{C}, 1 \mathrm{~h}$. Размер зерна после отжига составил 0.5-0.6 mm. Образцы испытывали в условиях ползучести при одноосном растяжении при комнатных условиях и напряжении $\sigma=80 \mathrm{MPa}$ до середины стационарной стадии, разгружали и после отжига при температуре в интервале от 100 до $300^{\circ} \mathrm{C}$ вновь испытывали при тех же условиях. На опыте определяли отношение $\alpha=\dot{\varepsilon}_{1} / \dot{\varepsilon}_{2}$ скоростей ползучести до $\left(\dot{\varepsilon}_{1}\right)$ и после $\left(\dot{\varepsilon}_{2}\right)$ промежуточного отжига. Дополнительно определяли концентрацию неравновестных вакансий $c_{v}$ и плотность дислокаций $N_{d}$ в деформированном алюминии. Величину $c_{v}$ оценивали по относительному разуплотнению $\Delta \rho / \rho$, а плотность дислокаций определяли из данных измерения среднего угла разориентации блоков $\bar{\theta}$ по формуле Хирша [10]: $N_{d}=\bar{\theta}^{2} / 9 b^{2}$, где $b-$ величина вектора Бюргерса дислокаций.

Рассмотрим вначале возможность иммобилизации дислокаций в алюминии (99.96wt.\%) с малым содержанием примесей. Примесные атомы $\mathrm{Fe}$, Ti и $\mathrm{Mn}$, содержание которых составило 0.035 at.\%, являются малорастворимыми и не участвуют в закреплении дислокаций. Атомные радиусы $r \mathrm{Si}$ и $\mathrm{Zn}$, содержание которых составило соответственно 0.011 и 0.003 at.\%, малы по сравнению с радиусом $r_{0}$ алюминия (их размерный фактор $\delta=\Delta r / r_{0}$ равен 0.06 и 0.03$)$, что исключает их взаимодействие с дислокациями $[4,10]$. Закрепляющими дислокации примесями являются атомы $\mathrm{Mg}$ и $\mathrm{Cu}$ с наибольшим размерным фактором 1.58 и 1.28 ; их суммарная концентрация $c_{0}$ составила $1 \cdot 10^{-2}$ at.\%. Степень насыщения дислокаций примесными атомами $c_{m}$ при 
температуре отжига $T_{0}$, согласно уравнению Максвелла, оценивается как [10]

$$
c_{m}=c_{0} \exp \left(W_{m} / k T_{0}\right),
$$

где $W_{m}=0.3 \mathrm{eV}[10]-$ энергия связи дислокация примесный атом, $k-$ постоянная Больцмана. При этом примесные атомы вдоль линии дислокации располагаются друг от друга на расстоянии $\lambda[10]$

$$
\lambda \approx b / c_{m} .
$$

Рассмотрим экспериментальные данные. На рис. 1 приведены зависимости $\alpha, \Delta \rho / \rho$ и $\bar{\theta}$ от температуры промежуточного отжига деформированных образцов алюминия. Видно, что упрочнение (рост величины $\alpha$ ) имеет место при температурах свыше $100^{\circ} \mathrm{C}$; максимальное упрочнение наблюдается при температуре отжига $180^{\circ} \mathrm{C}$. При этой температуре максимальная степень насыщения примесью, согласно (1), составляет $c_{m}=2 \cdot 10^{-2}$ at.\%, что значительно меньше максимальной степени насыщения равной 0.5 at.\% [10]. Примесные атомы, согласно (2), располагаются на расстоянии $\lambda=50 b$ друг от друга. Таким образом, при температуре отжига $180^{\circ} \mathrm{C}$ дислокации являются ненасыщенными. Следует отметить, что при последующем охлаждении до комнатной температуры примеси замораживаются, величины $c_{m}$ и $\lambda$ остаются неизменными и определяют поведение дислокаций при последующем нагружении [9].

Из данных рис. 1 также следует, что начало закрепления дислокаций совпадает с началом отжига разуплотнения $\Delta \rho / \rho$, величина которого определяет относительную концентрацию неравновестных вакансий [10]. Действительно, обработка данных изохронного и изотермического отжигов разуплотнения показала, что энергия активации отжига $\Delta \rho / \rho$ составляет для алюминия $(99.97 \mathrm{wt} . \%)$ $(0.75 \pm 0.05) \mathrm{eV}$ и $(0.45 \pm 0.05) \mathrm{eV}$ для $\mathrm{Zn}(99.9 \mathrm{wt} . \%)$, что практически совпадает с энергией миграции вакансий $E_{m \vartheta}$.

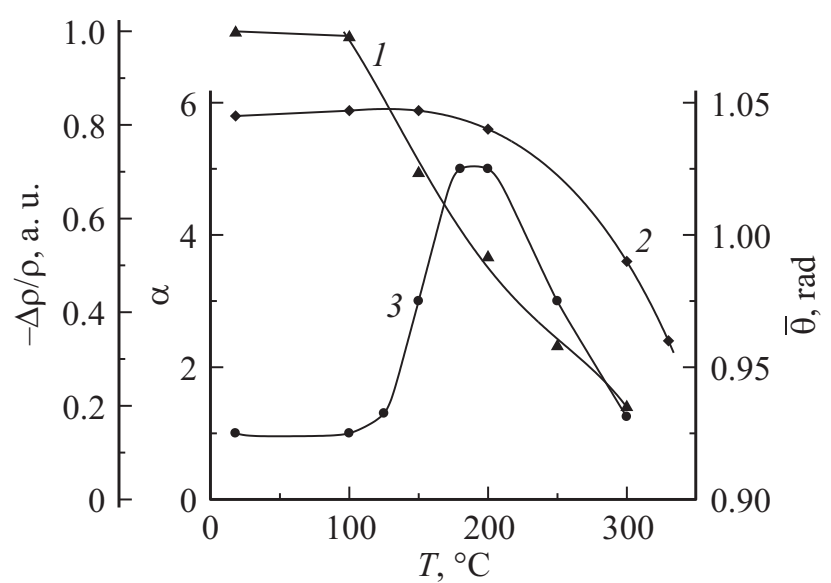

Рис. 1. Зависимость дефекта плотности $\Delta \rho / \rho(1)$, разориентация блоков $\bar{\theta}(2)$ и степени упрочнения $\alpha(3)$ от температуры промежуточного отжига $\left(t_{\text {ann }}=1 \mathrm{~h}\right)$ для деформированного $\mathrm{Al}$. За „1“ принято значение $-\Delta \rho / \rho=1 \cdot 10^{-4}$.

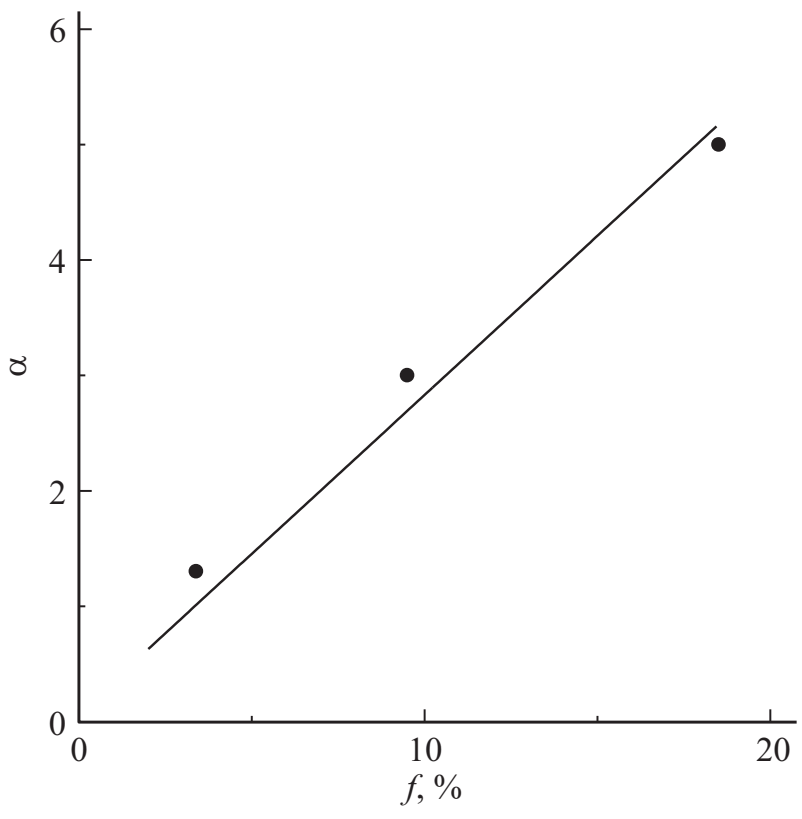

Рис. 2. Зависимость коэффициента упрочнения от доли атомов примеси, скапливающихся у дислокаций при отжиге деформированного алюминия.

Известно [9], что деформационные вакансии обеспечивают высокую диффузионную подвижность примесных атомов $D$ :

$$
D=\frac{1}{6} v b^{2} c_{v} \exp \left(-E_{m \vartheta} / k T_{0}\right),
$$

где $v=10^{13} \mathrm{~s}^{-1}$ - частота тепловых колебаний, $c_{v}$ относительная концентрация вакансий. При $T_{0}=180^{\circ} \mathrm{C}$, $c_{v}=6 \cdot 10^{-5}, b=3 \cdot 10^{-10} \mathrm{~m}, E_{m \vartheta}=0.72 \mathrm{eV}$ коэффициент диффузии $D=7.6 \cdot 10^{-20} \mathrm{~m}^{2} / \mathrm{s}$. За время отжига $t$ при температуре $T_{0}$ доля $f$ атомов примеси, исчезнувших из наклепанного твердого раствора определяется согласно выражению [9]:

$$
f=\pi N_{d}\left(3 W_{m} D b t / k T_{0}\right)^{2 / 3} .
$$

Из выражения (4) следует, что при $T_{0}=180^{\circ} \mathrm{C}$, $t=3.6 \cdot 10^{3} \mathrm{~s}$ и $N_{d}=2 \cdot 10^{14} \mathrm{~m}^{-2}$ доля атомов примеси, осевшая на дислокациях, составляет $f=0.185$. Аналогичные оценки, выполненные для других температур отжига, показали, что с увеличением температуры от 125 до $180^{\circ} \mathrm{C}$ доля примесных атомов, удерживающих дислокации, заметно меняется. Связь между величиной $f$ и коэффициентом упрочнения $\alpha$ представлена на рис. 2 .

При повторном нагружении линия дислокации удерживается рядом чужеродных атомов, поэтому для отрыва дислокации от примесей необходимо дополнительное усилие. В случае дислокации, не насыщенной примесью, дополнительное напряжение $\Delta \tau$, согласно [10], приблизительно равно

$$
\Delta \tau \approx W_{m}^{2} c_{0} / k T b^{3}
$$


Из (5) следует, что при $T=18^{\circ} \mathrm{C}$ и $c_{0}=1 \cdot 10^{-4}$, $\Delta \tau \approx 2.3 \mathrm{MPa}$. Сравним полученную величину с величиной максимального упрочнения, определяющего уменьшение скорости ползучести при повторном нагружении. Известно [10], что при умеренных температурах испытания зависимости скорости ползучести от сдвигового напряжения $\tau$ и температуры $T$ описываются выражением

$$
\dot{\varepsilon}=\dot{\varepsilon}_{0} \exp \left(-\left(E_{0}-V\left(\tau-\tau_{\mu}\right)\right) / k T\right),
$$

где $E_{0}-$ энергия активации, совпадающая с энергией самодиффузии, $\dot{\varepsilon}_{0}-$ кинетическая константа, $V$ активационный объем, $\tau_{\mu}-$ создаваемые дислокациями дальнодействиющее внутреннее напряжение. После закрепления дислокаций примесями эффективное напряжение $\left(\tau-\tau_{\mu}\right)$ уменьшается на $\Delta \tau$, величина которого, согласно (6), равна

$$
\Delta \tau=k T \Delta \ln \dot{\varepsilon} / V
$$

При $V=7.5 \cdot 10^{-27} \mathrm{~m}^{3}, \Delta \tau=0.9 \mathrm{MPa}$, т. е. величина того же порядка, что и $\Delta \tau$, следующая из выражения (5). Отметим, что в случае кручения чистого алюминия напряжение, необходимое для отрыва дислокаций от примеси, при $T=18^{\circ} \mathrm{C}$ составило величину $0.5 \mathrm{MPa}$ [12], что близко к нашей оценке.

При температурах отжига свыше $180^{\circ} \mathrm{C}\left(0.5 T_{m}, T_{m}-\right.$ температура плавления) уменьшение величины $\alpha$ происходит как вследствие увеличения подвижности дислокаций из-за их отрыва от примесных атомов, так и вследствие уменьшения плотности дислокаций в границах блоков, на что указывает уменьшение после $180^{\circ} \mathrm{C}$ величины $\bar{\theta}$ (рис. 1).

Таким образом, проведенные оценки показали, что наблюдаемое в результате промежуточного отжига деформированного алюминия упрочнение обусловлено закреплением дислокаций примесными атомами. Определен температурный интервал закрепления дислокаций от 100 до $180^{\circ} \mathrm{C}$ и интервал температур свыше $180^{\circ} \mathrm{C}$, где подвижность дислокаций восстанавливается.

Авторы выражают искреннюю признательность Г.А. Малыгину за обсуждение результатов и ценные замечания.

\section{Список литературы}

[1] Betehtin V.I., Kadomsev A.G., Petrov A.I., Vladimirov V.I. // Phys. Stat. Sol. A. 1976. Vol. 34. P. 73-78.

[2] Бетехтин В.И., Владимиров В.И., Кадомцев А.Г., Петров А.И. // Поверхность. Физика, химия, механика. 1984. № 7. С. 144.

[3] Черемский П.Г., Слезов В.В., Бетехтин В.И. Поры в твердом теле. М.: Энергоатомиздат, 1990. $374 \mathrm{c.}$

[4] Бетехтин В.И., Кадомщев А.Г. // ФТТ. 2005. Т. 47. Вып. 5. C. $801-807$.

[5] Бриджмен П. Исследование больших пластических деформаций и разрыва. М.: ИЛ, 1955. 362 с.
[6] Давиденков Н.Н., Спиридонова Н.И. // Заводская лаборатория. 1945. Т. 11. Вып. 6. С. 583-593.

[7] Brownzigg A., Spitzig A. et al. // Acta Metall. 1983. Vol. 6. N 4. P. 785-790.

[8] Петров А.И., Разуваева М.В. // ЖТФ. 2014. Т. 84. Вып. 2. C. $35-38$.

[9] Коттрелл А.X. Дислокации и пластическое течение в кристаллах. М. 1958. 267 с.

[10] Фридель Ж. Дислокации. М.: Мир, 1967. 634 с.

[11] Малыгин Г.А., Владимирова Г.В. В кн.: Физические процессы пластической деформации при низких температуpax. Киев: Наукова Думка, 1974. С. 351-357.

[12] Мальгин Г.А., Владимирова Г.В., Привалова Н.Н. // ФММ. 1983. Т. 55. Вып. 5. С. 1005-1015. 